\section{Mechanism of Feeding in Blood-sucking Diptera}

IN a previous communication ${ }^{1}$ I reported the discovery of a sucking stylet in ticks which, to all appearances, was the homologue of the hypopharynx in other blood-sucking arthropods. On the analogy of the feeding mechanism in ticks, it seemed reasonable to postulate that in biting flies the food-channel is not formed by the apposition of the labrum. epipharynx and the hypopharynx, as has hitherto been supposed, but that it is represented exclusively by what has until now been regarded as the hypopharyngeal extension of the salivary duct. I referred to this tentative conclusion at the meeting of the Royal Entomological Society of London held on October 3, $1934^{2}$. I have now carried out numerous dissections upon freshly killed specimens of Stomoxys calcitrans. As will appear from Figs. 1 and 2, the labrum-epipharynx in this species of fly is entirely unconnected with the buccal chamber and is practically separated from the hypopharynx by an inward thrust of the apodeme, whilst the buccal chamber itself is continued directly into the expanded proximal portion of the hypopharynx, with the salivary duct terminating distally at this point.

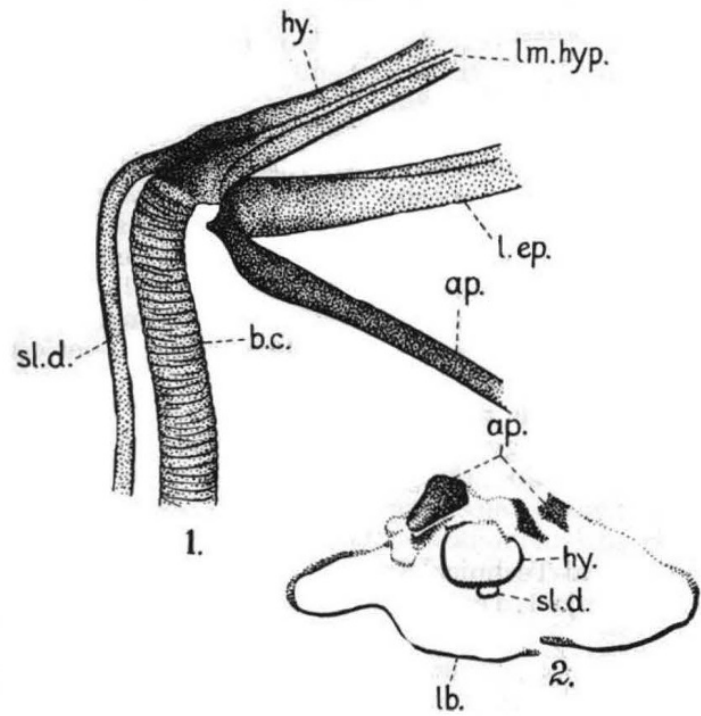

FIG. 1. Buccal chamber and the proximal portion of the mouth parts of Stomoxys calcitrans (the labium is not shown). Side view : labrum-epipharynx; lm.hyp., lumen of hypopharynx ; sl.d., salivary duct. $\times 90$.

Fig. 2. Transverse section through the mouth-parts of $S$. calcitrans at level of articulation of the apodemes : ap., apodemes; hy., hypopharynx ; lb., labium; sl.d., salivary duct. $\times 110$.

Furthermore, in fresh specimens the hypopharynx is seen to be provided with a distinct orifice at its distal extremity, and its tubular character is shown by the fact that, when the flies are fed on a suitable colouring substance (for example, hæmatoxylin) that has previously been sweetened with sugar, the hypopharynx takes the stain along the entire length of the walls of its lumen, while its external surface retains its normal colour.

Imperial Institute of Veterinary Research, S. K. SEN.

\section{Muktesar-Kumaun, U. P., India.}

April 11.

1 Nature, 134, $644 ; 1934$

2 Proc. Roy. Ent. Soc., 9, 76; 1934

\section{Trichromic Vision}

THE trichromics, that is those who see three colours in a bright spectrum, red, green and violet, are confused by many with the anomalous trichromatics, whereas they are quite distinct. The anomalous trichromatics, as defined by the late Lord Rayleigh, make an anomalous equation and do not agree with the normal equation, and they may not be colourblind. The trichromics are invariably dangerously colour-blind, and though they may make an anoma. lous equation they may also agree with the normal equation.

The following case will make this clear. Examined with Ishihara, read all the figures with the ease and rapidity of a normal sighted person. Examined with lantern, called red, white; white, red; green, red; and green, white. Tested by colour equations, 10 red, $\lambda 633+10$ green $\lambda 540$, being the normal equation, matching the light of the arc. Made equations ranging from $10 \mathrm{red}+33$ green to $10 \mathrm{red}+5$ green. He also made the normal equation. The luminosity in each case was correct. Saw three colours in the spectrum red, green, and violet; described $\lambda 585$ as red mottled, saw green at $\lambda 574$, named isolated division $\lambda .553 \cdot 5-\lambda .598$ as all green.

It will be seen that this case appears both as a high grade red anomaly, a high grade green anomaly and he also made the normal equation. It will be noticed that the trichromic in conditions of difficulty, as for example with small lights, make dichromic mistakes.

\section{Board of Trade, \\ London, S.W.1. May 3.}

\section{F. W. EDRIDGE-GREen.}

\section{Vitamin and Nitrogenous Food Requirements of the True Lactic Acid Bacteria}

IT has now been successfully shown in this laboratory that all the lactic acid bacteria, Streptococci as well as rod-shaped forms, demand an alkali stable substance, related to bios, for their growth. The rod forms require, in addition to this substance, lactoflavin and possibly still another activator.

Earlier research seems to indicate that the true lactic acid bacteria are very fastidious in their requirements as to nitrogenous food. Without knowledge of the facts mentioned above, it has been impossible to study this question because the lactic acid baeteria do not grow in a complete mixture of the amino acids present in genuine proteins when activators are absent. It has now been found that the Thermobacteria show just as narrow requirements as regards nitrogenous food as do the higher animals, and for some species the requirements are even still more specialised. On the other hand, the Streptobacteria are satisfied with ammonia salts and a trace of cysteine, and the Streptococci even with ammonia salts as the sole source of nitrogen.

A detailed report will be published shortly.

\section{S. OrLa-Jensen.}

Biotechnical-chemical Laboratory, Royal Technical College, Copenhagen. 